\title{
I 07 I Interobserver variability differences for cardiac MRI right ventricular (RV) volumetry and mass measures between standard and "modified" right ventricular short axis imaging in patients with chronic pulmonary insufficiency
}

\author{
Amy Tipton*, Robert Fleck, Eric Crotty, Kathy Helton, Kan Hor, \\ Janaka Wansapura and William Gottliebson
}

Address: Cincinnati Childrens Hospital and Medical Center, Cincinnati, OH, USA

* Corresponding author

from I th Annual SCMR Scientific Sessions

Los Angeles, CA, USA. I-3 February 2008

Published: 22 October 2008

Journal of Cardiovascular Magnetic Resonance 2008, I0(SuppI I):AI96 doi:10.I I86/I532-429X-I0-SI-A196

This abstract is available from: http://jcmr-online.com/content/I0/SI/AI96

(c) 2008 Tipton et al; licensee BioMed Central Ltd.

\section{Introduction}

Standard MRI assessment of right ventricular (RV) volume and mass is based on assessment of a stack of "standard" short axis images (fig. 1) obtained with respect to the horizontal long axis of the heart. A "modified" RV short axis stack of images, based on cross-sections of the RV outflow long axis (fig. 2), has recently been demonstrated to overcome observed inaccuracies in definition of the tricuspid valve plane for the "standard" image stacks, and therefore to result in less interobserver variability and more reliable $\mathrm{RV}$ volume estimates in subjects with anatomically and functionally normal RVs.

\section{Purpose}

To determine if the "modified" RV short axis stack would decrease interobserver variability of MRI RV measurements in patients with dilated RVs due to chonic pulmonary insufficiency from previously repaired Tetraolgy of Fallot.

\section{Methods}

Prospective comparison of cardiac MRI scans of 9 adolescent/young adult patients ( 5 male, age range 10 to 25 years) with a diagnosis of TOF status post infantile/childhood transannular patch repair. Subjects underwent cardiac MRI for standard clinical indication on either a GE 1.5 Tesla Excite or a Siemens 3 Tesla Trio magnet. In addi- tion to standard short axis cine SSFP stacks, a second stack of "modified" RV short axis SSFP cines was obtained perpendicular to the RV outflow long axis. RV volumetry and mass were assessed by planimetry of the endocardial and epicardial RV borders at end systole and end-diastole using Medis MASS software. RV volume and mass were measured for both sets of RV short axis stacks by 5 independent expert observers blinded to one another's data. Data were analyzed by comparison of mean standard deviations for each of the two methods.

\section{Results}

Mean interobserver standard deviations for RV enddiastolic volume were $10.3 \mathrm{~mL}$ (modified) vs $15.2 \mathrm{~mL}$ (standard) and for RV end-systolic volume were $12.8 \mathrm{~mL}$ (modified) vs $17.7 \mathrm{~mL}$ (standard). Standard deviations in $\mathrm{RV}$ mass measurement were $9.1 \mathrm{~g}$ (modified) vs $7.3 \mathrm{~g}$.

\section{Conclusion}

The modified RV short axis cine stack showed improved reproducibility in estimation of RV volume measurments as compared to the standard RV short axis stack in this limited series of patients with volume overloaded RVs. 


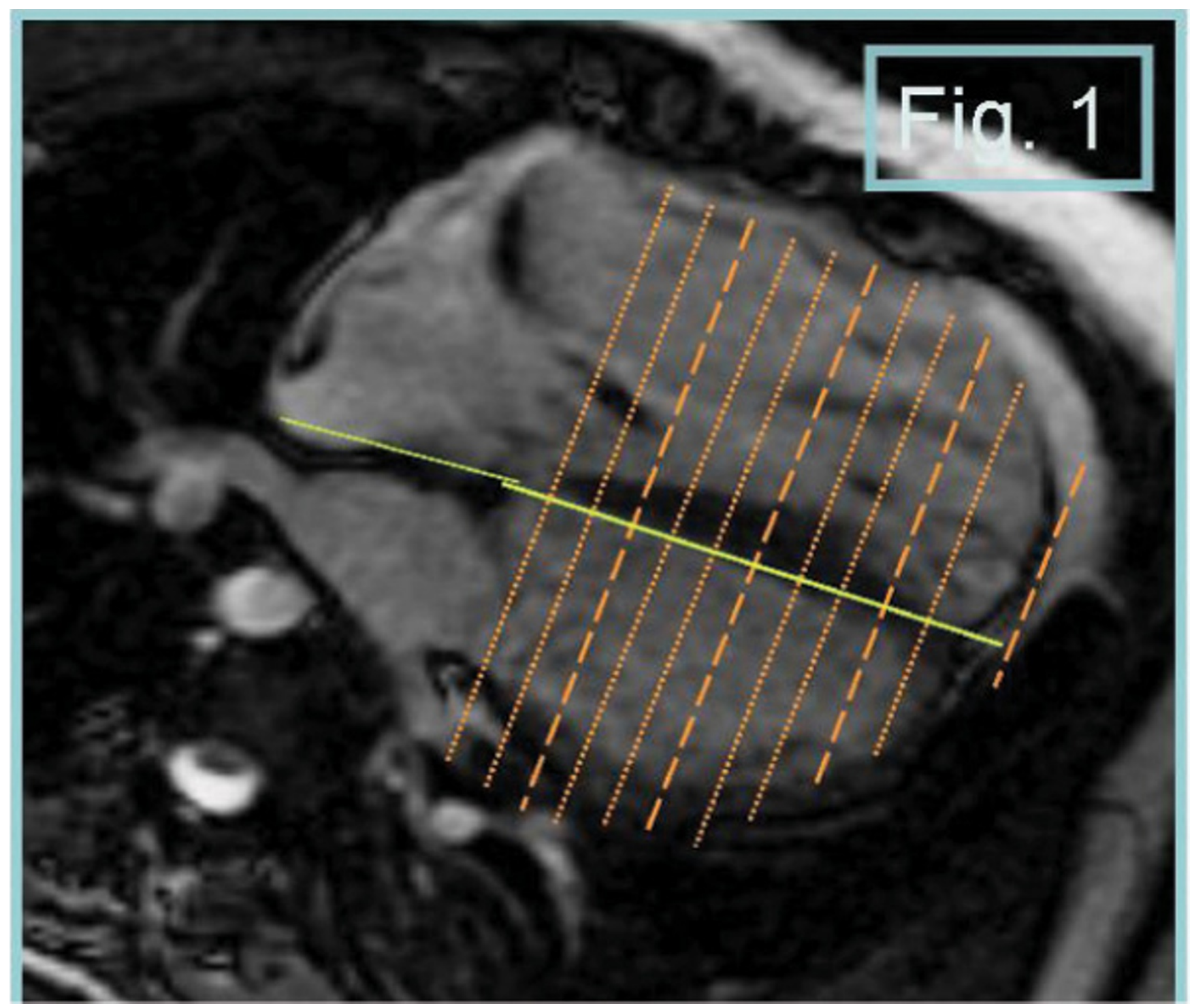

Figure I 


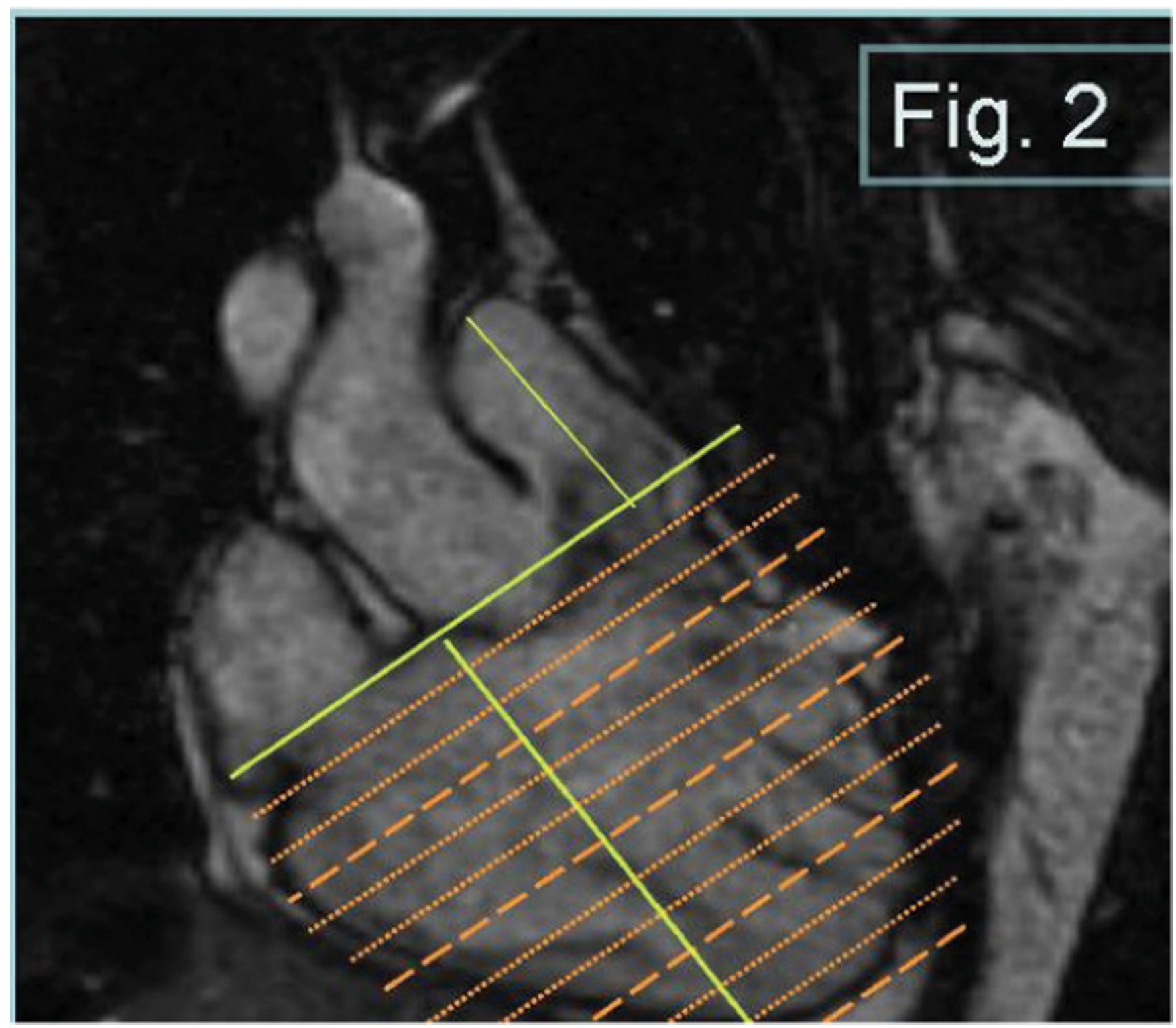

Figure 2

Publish with Biomed Central and every scientist can read your work free of charge

"BioMed Central will be the most significant development for disseminating the results of biomedical research in our lifetime. " Sir Paul Nurse, Cancer Research UK

Your research papers will be:

- available free of charge to the entire biomedical community

- peer reviewed and published immediately upon acceptance

- cited in PubMed and archived on PubMed Central

- yours - you keep the copyright 